\title{
Reflexões sobre a prática de ateliê com alunos iniciantes de arquitetura e urbanismo
}

\author{
Zilsa Maria Pinto Santiago \\ Doutora, Professora Adjunta, \\ Universidade Federal do Ceará \\ zilsa@arquitetura.ufc.br
}

Débora de Oliveira Sousa Designer, Graduanda de Arquitetura e Urbanismo, Universidade Federal do Ceará, debora.oliveira.sousa@hotmail.com
RESUMO:

Trata de breve relato sobre experiência de ensino-aprendizagem em ateliê na Unidade de Percepção e Representação da Forma no Curso de Arquitetura e Urbanismo da Universidade Federal do Ceará. A pretensão é registrar como se processa o ensino-aprendizagem no ateliê de Desenho Arquitetônico com metodologias didáticas teórico-práticas de aprender-fazendo, no sentido de contribuir para discussões sobre o assunto, visto que as especificidades do processo de ensino-aprendizagem num curso cuja natureza de ação e essência do currículo circulam entre a técnica e a arte; a teoria e a prática, ousamos afirmar que a complexidade do cotidiano da prática docente em ateliê de desenho, quando observado sob a perspectiva do saber-fazer do professor e do aluno leva ao entendimento da complexidade do trabalho pedagógico e seus processos interativos, fazendo desta experiência um campo privilegiado de pesquisa. Com este texto, esperamos trazer algumas reflexões sobre o ensino superior e a prática no ateliê de Desenho Arquitetônico com alunos do segundo semestre, tendo em vista que a universidade é um campo de ação do professor não apenas na sala de aula, mas um lugar de ação articulada entre os saberes e lugares, onde os conhecimentos sistematizados permeiam o ensino na sua teoria e prática. Palavras-chave: Arquitetura; Teoria x Prática; Ateliê de Desenho. 


\section{INTRODUÇÃO}

Ainda na infância, o desenho surge como forma de expressão do mundo novo que a cada dia é descoberto. Sem pretensões ou preocupações representativas, de forma mais lógica que visual (Luquet, 1927 apud Araújo, 2014) as crianças demonstram seu modo de ver o mundo (como é) e afloram a imaginação (como imaginam) através de traços e rabiscos despretensiosos.

Conforme os anos passam os meios de aprendizagem e métodos de ensino dirigem o jovem estudante para currículo básico e formatado para objetivos específicos, com disciplinas do âmbito do currículo padrão e, na maioria das vezes sem nenhuma preocupação com o desenvolvimento criativo e expressivo desses alunos. Mesmo disciplinas voltadas para esse viés não recebem a devida atenção por parte dos alunos e nem do corpo docente, já que por vezes as disciplinas "artísticas" são tomadas por professores substitutos ou não tem um conteúdo representativo.

Essa liberdade criativa e essa aproximação do desenho acabam sendo cerceados e aparece o receio de julgamento, necessidade de aprovação e, normalmente na fase da adolescência, os desenhos deixam de ser utilizados/elaborados. Isso porque não mais se bastam por cumprir sua propriedade expressiva, mas precisam resultar em produtos artísticos aprovados esteticamente por princípios, conceitos e outros critérios. Os desenhos passam a ser padronizados, sendo representados como são ensinados e, não como são vistos pelo autor nem por livre espontaneidade. Esse julgamento distancia os estudantes do desenho, sendo isso ainda mais problemático quando estes estudantes passam a integrar áreas onde o desenho faz parte de sua metodologia de trabalho.

O desenho possui propriedades investigativas, criativas e expressivas. (ARAUJO, 2014) e está ligado ao homem desde a sua necessidade de se expressar.

\footnotetext{
"O desenho, uma língua tão antiga e tão permanente, atravessa a história, atravessa todas as fronteiras geográficas e temporais, escapando da polêmica entre o que é novo e o que é velho. É fonte original de criação e invenção de toda sorte, o desenho é exercício da inteligência humana." (Derdyk,1988,p.32)
}

No campo da Arquitetura, a falta de intimidade com o desenho é ainda mais problemática devido à necessidade intrínseca deste. Ao longo da História da Arquitetura, o desenho tem se mostrado como uma linguagem inerente ao arquiteto. Segundo Ramirez (1990), trata-se de um "instrumento tão essencial como a própria construção".

Durante o Renascimento, período em que houve a divisão de trabalho entre quem criava o projeto e quem construía, viu-se a necessidade de repassar as informações antes concentrada no criador-executor e estas agora deveriam ser registradas permitindo a qualquer um, que domine os códigos envolvidos, a possibilidade de interpretação. 
O desenho, além da propriedade representativa, expressão de uma ideia consolidada, auxilia na descoberta dessa ideia, no processo criativo e na tradução do pensamento. Com base no estudo de Batle (2011), sobre o desenho na Arquitetura, podemos definir duas vertentes de comunicação: o diálogo entre o arquiteto e ele mesmo (onde o desenho auxilia nas tomadas de decisão, percepção do espaço, experimentação) e o diálogo do arquiteto com os outros (a transmissão das decisões já definidas em linguagem padronizada permitindo seu entendimento por qualquer outra pessoa capacitada com o conhecimento do código apresentado).

Para o estudante de Arquitetura se faz necessário o completo entendimento de tais códigos para que possa desenvolver seus projetos ao longo do curso e também da vida profissional. Entretanto, a falta de familiaridade com o desenho devido o distanciamento deste como auxílio de percepção, por longo tempo, acaba por dificultar todo o processo.

Seja com função representativa ou como metodologia projetual, se faz necessário uma série de fundamentos que auxiliem o aluno a reencontrar o contato com o desenho, agora em uma nova perspectiva e nível. Disciplinas como Desenho de Observação, Geometria Descritiva e o Desenho Técnico são instrumentos de formação que, aos poucos, preparam o aluno para decodificação dos códigos de representação, ao mesmo tempo que os levam à compreensão espacial por meio do entendimento do desenho. 0 objetivo da redescoberta do desenho pelo estudante de Arquitetura, como fonte de expressão e desenvolvimento de ideias, amplie o processo facilitando o desenvolvimento do seu potencial perceptivo, representativo e criativo.

0 presente trabalho tem como objetivo analisar o processo de ensinoaprendizagem do desenho e dos novos processos de representação no desenvolvimento da percepção espacial por parte do aluno de Arquitetura. Especificamente, entender como a metodologia do ensino em Ateliê favorece o aprendizado.

\section{METODOLOGIA}

Para o entendimento do processo de ensino-aprendizagem, inicialmente foram pesquisados o histórico do desenho buscando entender sua relação com a expressividade humana e o processo criativo, bem como ele reflete a percepção do observador. Somando a isso buscamos compreender o processo de aprendizagem e ensino no ateliê e suas repercussões na prática projetual dos futuros arquitetos. Através da experiência com monitoria de desenho arquitetônico, foi possível acompanhar um estudo de caso da prática do aprender-fazendo (SCHÖN, 2000) na Disciplina de Desenho Arquitetônico e seus impactos nos alunos do Curso de Arquitetura e Urbanismo da Universidade Federal do Ceará. 


\subsection{Fundamentação Teórica}

A metodologia de ensino no campo da Arquitetura se apresenta de modo diferenciado, quando comparado com outras áreas, servindo de exemplo para estudos de metodologia de ensino. Por muitas vezes o ensino de um conteúdo acontece por meio de um professor que transmite um conteúdo programado anteriormente e de forma coletiva para os ouvintes enquanto o aluno, de forma passiva recebe a informação, tomando muitas vezes esta como verdade, mas, muitas vezes, sem nenhum tipo de aplicação.

A premissa do ensino de ateliê prevê outro tipo de metodologia, pautada na apresentação de situações-problema ao aluno onde o professor abandona o posto de detentor absoluto do conhecimento e passa a ser um aliado do estudante buscando juntos a solução mais adequada ao seu problema.

Um estudioso da área, Donald Schön, discorre sobre a prática do profissional reflexivo. Inicialmente Schön traz à tona uma reflexão sobre o ensino padrão focado na especialização e com uma visão tecnicista na resolução dos problemas. Em contrapartida discorre sobre a necessidade do profissional ser mais humano e criativo. Cada problema, embora possua similaridades, é um problema diferente e único, e por muitas vezes não se enquadra em fórmulas pré-concebidas, sendo necessário, por parte de quem busca resolver a situação, talento artístico profissional para o entender a aplicação do seu repertório em diferentes problemáticas.

Para uma boa formação profissional o estudante precisa perceber as demandas que surgem em sua profissão, em forma de simulações. 0 ensino prático demanda do aluno uma imersão em uma situação problema para que possa, pensando como profissional, fundamentado nos conteúdos estudados/pesquisados, encontrar a melhor forma de resolvê-lo. 0 professor funciona como um facilitador do processo deixando o aluno descobrir suas próprias soluções: (...) e o instrutor não tenta explicar tais coisas (...) porque elas somente podem ser compreendidas na experiência real do projeto (SCHÖN, 2000, p.73).

A proposta de conhecer-na-ação é resultado de respostas espontâneas dadas a determinado problema, que se enquadre nos limites normais, para alcançar os resultados pretendidos. Por vezes às respostas espontâneas não se adequam à situação em questão, devido à multiplicidade de situações e problemáticas. Esse momento, em que a responde habitual não se encaixa é o maior momento de crescimento do aluno, ou profissional.

Instigado pelo novo desafio que se apresenta acontece a reflexão-naação, para transformar o repertório de conhecimento em soluções aplicáveis a situação. A reflexão-na-ação tem uma função crítica, discutindo sobre o nosso conhecer-na-ação sobre como se deu esse processo e como poder encontrar novas alternativas para o problema.

A reflexão gera um experimento imediato. Pensamos um pouco e experimentamos novas ações com o objetivo de explorar os 
fenômenos recém-observados, testar nossas compreensões experimentais acerca deles, ou afirmar as ações que tenhamos inventado para mudar as coisas para melhor. (SCHÖN, 2000, p. 3334).

A prática reflexiva permite um aprimoramento constante durante todo o processo de aprendizagem e de projetação. É preciso ter consciência do método de análise e síntese que surgem na sua ação, para que possam assim serem refletidas conforme acontecem (reflexão na ação).

\section{CONTEXTUALIZAÇÃO DO ATELIÊ DE DESENHO NO CURSO}

0 aluno de Arquitetura e Urbanismo, quando inicia o curso, se depara com uma série de novos códigos, sensações e percepções, ao mesmo tempo que lhes é exigido a representação de todos esses novos conceitos que está adquirindo. Devido ao desligamento com o desenho ainda na infância ou adolescência, bem como a falta de disciplinas que trouxesse essa relação mais próxima entre percepção e expressão no decorrer de sua formação escolar básica, muitos alunos têm dificuldades ao se deparar com as disciplinas iniciais do curso que exigem um raciocínio espacial e uma percepção tridimensional do espaço e dos objetos. A exceção a essa regra pode ser percebida por alunos que tiveram um contato prévio com essa metodologia, como alunos que, antes da faculdade, passaram por ou por cursos técnicos, ou desenvolveram esta habilidade em cursos complementares e se exercitaram continuamente, assim, chegam com uma boa base de percepção tridimensional e representação.

As disciplinas que fundamentam os princípios de percepção do espaço para o desenvolvimento técnico projetual são as de Geometria Descritiva, Desenho de Observação e Desenho Arquitetônico, aliados a de Espaço e Forma, podendo variar de acordo com o currículo adotado pela universidade. Nos dois primeiros semestres é feita esta imersão conceitual e gestáltica da percepção e representação. Posteriormente, o aluno segue consolidando e fixando os conceitos ao longo do curso.

O desenho de observação tem como principal função reatar a ligação entre o aluno e o desenho como forma de expressão e observação direta das formas, proporções, simetria. 0 estudante tem o seu olhar treinado para uma melhor percepção dos contornos e texturas e assim, poder representar com mais precisão o que vê e não a imagem que lhe foi ensinada de determinada forma. Diversos exercícios são desenvolvidos na busca da apreensão dos detalhes e do desprendimento de qualquer barreira que o aluno possa ter com o desenho. 0 traço, a escrita, a perspectiva começam a ser treinados e a fazer parte do novo código e universo do repertório do aluno. Nessa etapa o aluno não utiliza nenhum outro tipo de instrumento, a não ser o lápis/grafite, fazendo todo o tipo de desenho à mão livre.

$\mathrm{Na}$ disciplina de Geometria Descritiva costuma ser trabalhado o método de Monge, por isso também é conhecida como Geometria Mongeana. Através da épura, representação num plano de qualquer entidade geométrica, mediante projeções ortogonais e oblíquas, os alunos começam a entender que 
tudo ao seu redor pode ser representado por pontos, linhas, planos e volumes. Esse entendimento é crucial para a representação gráfica desta fase e de fases posteriores, mesmo que venha a utilizar outros mecanismos ou instrumentos como o computador.

A disciplina de Desenho Arquitetônico (DA) trata, em síntese, da correta representação gráfica do objeto arquitetônico por meio de elementos historicamente utilizados na Geometria Mongeana, como plantas, fachadas, cortes e desenhos isométricos, dimétricos e projeções oblíquas, além de introduzir questões construtivas. Cursada ainda no início da formação, é uma disciplina básica que oferece o conteúdo indispensável para o desenvolvimento do curso.

\section{ESTUSO DE CASO - ATELIÊ DE DESENHO ARQUITETÔNICO}

Ao acompanhar o andamento da disciplina de Desenho Arquitetônico do Curso de Arquitetura da Universidade Federal do Ceará de forma sistemática de pesquisa é possível entender como se dá essa vivência e a evolução do aluno perante sua condição de percepção do espaço tridimensional, e o entendimento e aplicação das normas de representação.

A metodologia do curso é aplicada por meio de aulas expositivas e ateliê. Assim sendo, o auxílio de monitores permite um acompanhamento mais próximo do aluno, sendo possível perceber suas maiores dificuldades durante o curso; o avanço no decorrer dos exercícios e o ganho de cada um pelo conhecimento adquirido que ultrapassa a disciplina e irá embasar toda a sua vida profissional.

A complexidade do ensino de desenho arquitetônico se mostra pela dificuldade do entendimento, por parte do aluno, da abstração proveniente do desenho como representação, como signo. Conforme Tostrup (1999, p.25), ninguém nunca viu um objeto ortogonal, este é uma construção abstrata. Esse domínio da visão espacial embora tenha sua introdução no semestre anterior, se consolida, e em certos casos se adquire, na disciplina de DA.

Além da compreensão do desenho ortogonal, as normas para representação arquitetônica se mostram como um grande impasse a ser superado. A assimilação de uma linguagem universal de representação causa estranheza aos alunos habituados a um desenho mais expressivo e espontâneo, como o desenho a mão livre (em Desenho de Observação) trabalhado no semestre anterior. A utilização de regras para espessura de linhas, indicações, tamanho de texto, diferenciação entre o que é cortado e visto constituem uma série de diretrizes e/ou signos a serem representados e/ou seguidos para o desenvolvimento de representação de projeto. Sobre a importância desse conhecimento Gildo Montenegro (1997), assinala que o Desenho Arquitetônico deve ser dominado até os seus pormenores mais sutis. O futuro arquiteto terá de conhecer a fundo a gramática (regras) do desenho, a fim de se expressar fácil e rapidamente na linguagem do traço. 
A disciplina se inicia com uma aplicação prática dos conceitos apreendidos anteriores em Geometria Descritiva: retas e planos. Nesse momento esses elementos são usados para passar os primeiros conceitos de desenho e tridimensionalidade ao propor que os alunos desenvolvam volumes e posteriormente cobertas em planta, vistas e perspectiva. Os alunos além de estarem trabalhando a visão espacial estão tendo o primeiro contato com os materiais de desenho: esquadros, gabaritos, escalímetro, compasso; e com as primeiras regras de representação: diferença de espessura de linhas para planos distantes, traço contínuo, uso da hachura, hierarquia no desenho de acordo com a informação etc.

Nesta etapa, os desenhos se resumem a sólidos em tamanhos menores, papel em formato A4 para facilitar esse primeiro contato dos alunos com os instrumentos. 0 exercício é entregue ao aluno em vista superior e vista lateral. Partindo do entendimento destas vistas, ele deve elaborar planta baixa, corte e desenhos oblíquos e axonométricos, observando que cada vez que elabora uma representação vai paulatinamente dominando a tridimensionalidade do objeto. É a aplicação da técnica de ensinoaprendizagem do aprender-fazendo (SCHÖN, 2000).

Figura 1: Exemplo de exercício desenvolvido pelos alunos na primeira etapa da disciplina: um sólido em perspectiva isométrica

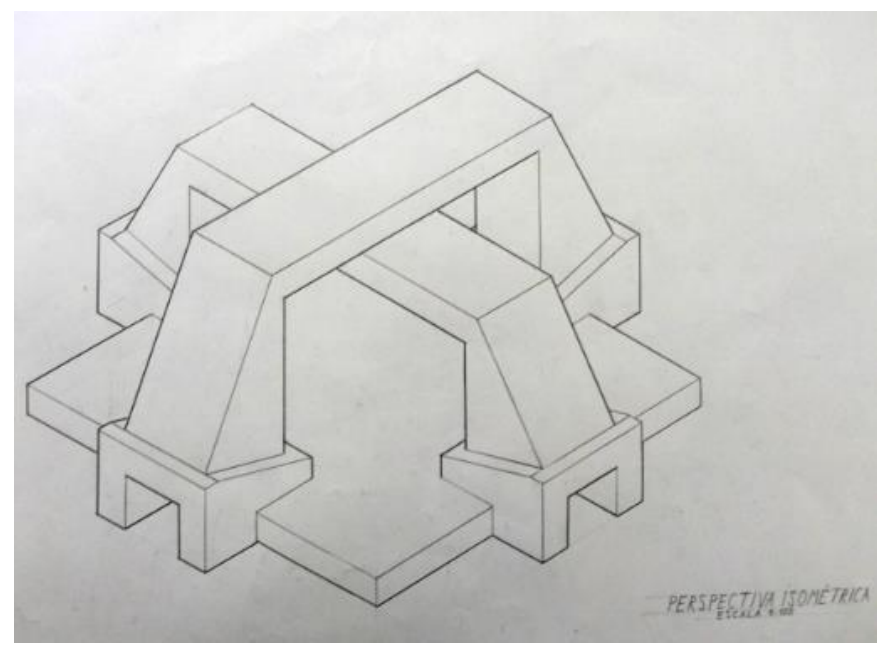

Fonte: Arquivo Disciplina Desenho Arquitetônico (2014)

Foto 1 e 2: Alunos da disciplina desenvolvendo os exercícios e apreendendo a manusear os instrumentos.

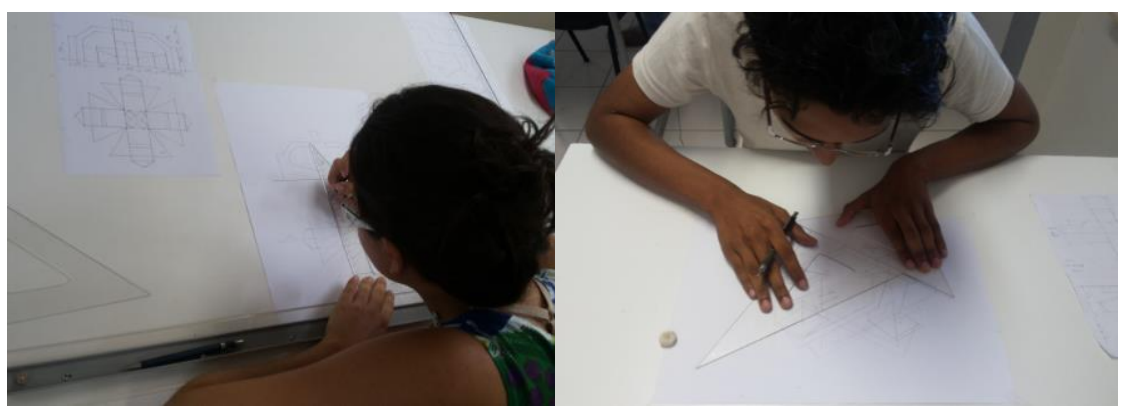

Fonte: Arquivo Disciplina Desenho Arquitetônico (2014) 
Na etapa seguinte se iniciam os desenhos em pranchas A1. Os alunos devem desenvolver em dupla dois exercícios: o levantamento métrico/gráfico de escadas e de esquadrias. A disciplina, nesta etapa, propicia uma vivência bastante importante para o aluno e que dificilmente se repete durante o curso: o levantamento gráfico/métrico. No exercício de representação de escadas e esquadrias além da prática representativa ser desenvolvida, os alunos são estimulados não a desenharem todos um mesmo objeto, mas cada dupla de alunos fará a medição do seu objeto escolhido na cidade, sob a orientação do professor. Isso permite uma maior apropriação e entendimento de cada peça não apenas com relação a tamanhos, mas a função destes para o elemento arquitetônico. Além da motivação da escolha, o trabalho da turma como um todo, vai se constituir de muitos exemplares diferentes, enriquecendo assim as trocas, as experiências pela diversidade de elementos a serem entendidos e desenhados.

Para conseguirem absorver o maior número de informações possível na atividade de levantamento das escadas, a dupla deve buscar dois tipos de desenho: uma escada linear e uma helicoidal. Do mesmo modo, em esquadrias, devem entregar uma porta e uma janela. Nessas etapas além de representação em planta, vista e corte os alunos trabalham com detalhamentos e especificação de materiais, tendo, pela primeira vez, a oportunidade de imersão nesses novos conceitos construtivos e assim, por similaridade, passam por uma experiência que se aproxima da etapa de projeto executivo. Aqui, é discutida a condição inversa do real para a abstração do desenho. Resumindo num fluxograma a seguir:

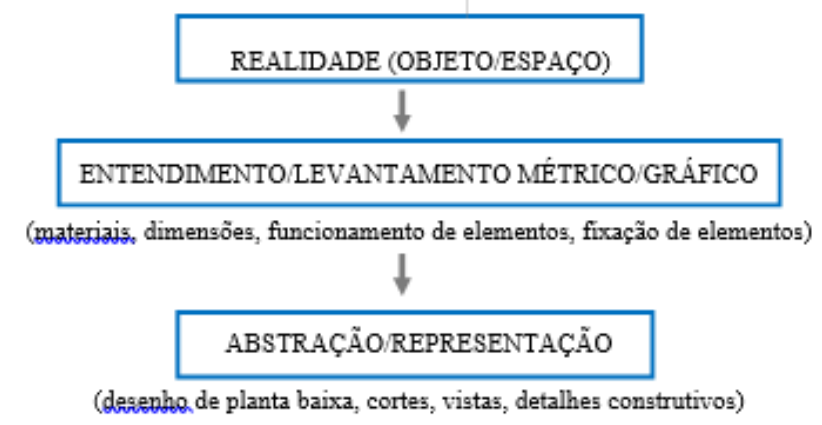

Figura 2 e 3: Exemplos de croquis desenvolvidos pelos alunos durante o levantamento métrico. À esquerda, escada helicoidal, e à direita escada linear.

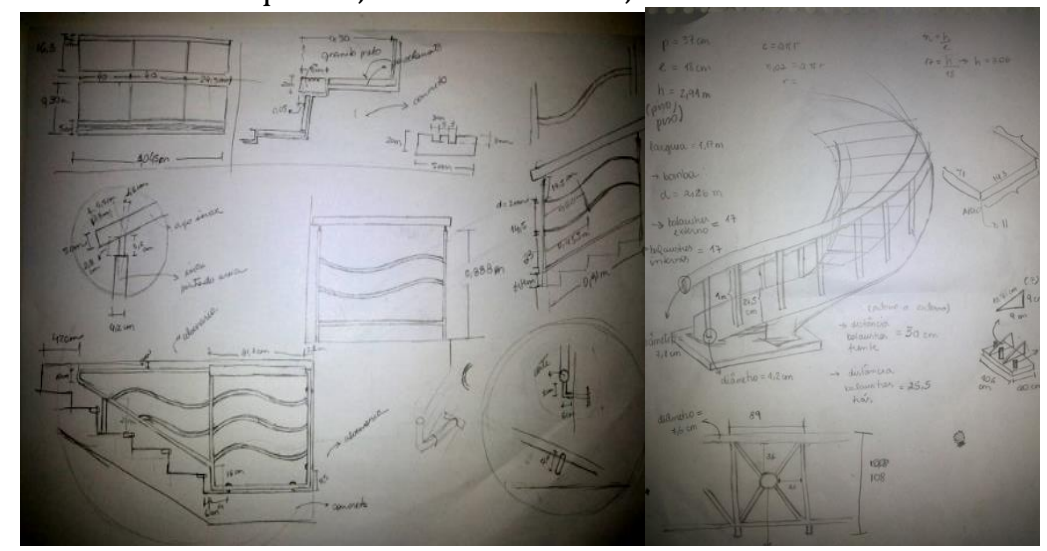

Fonte: Arquivo Disciplina Desenho Arquitetônico (2014). 
Figura 4, 5 e 6: Exemplos de desenho final entregue pelos alunos referente ao exercício de escada linear.
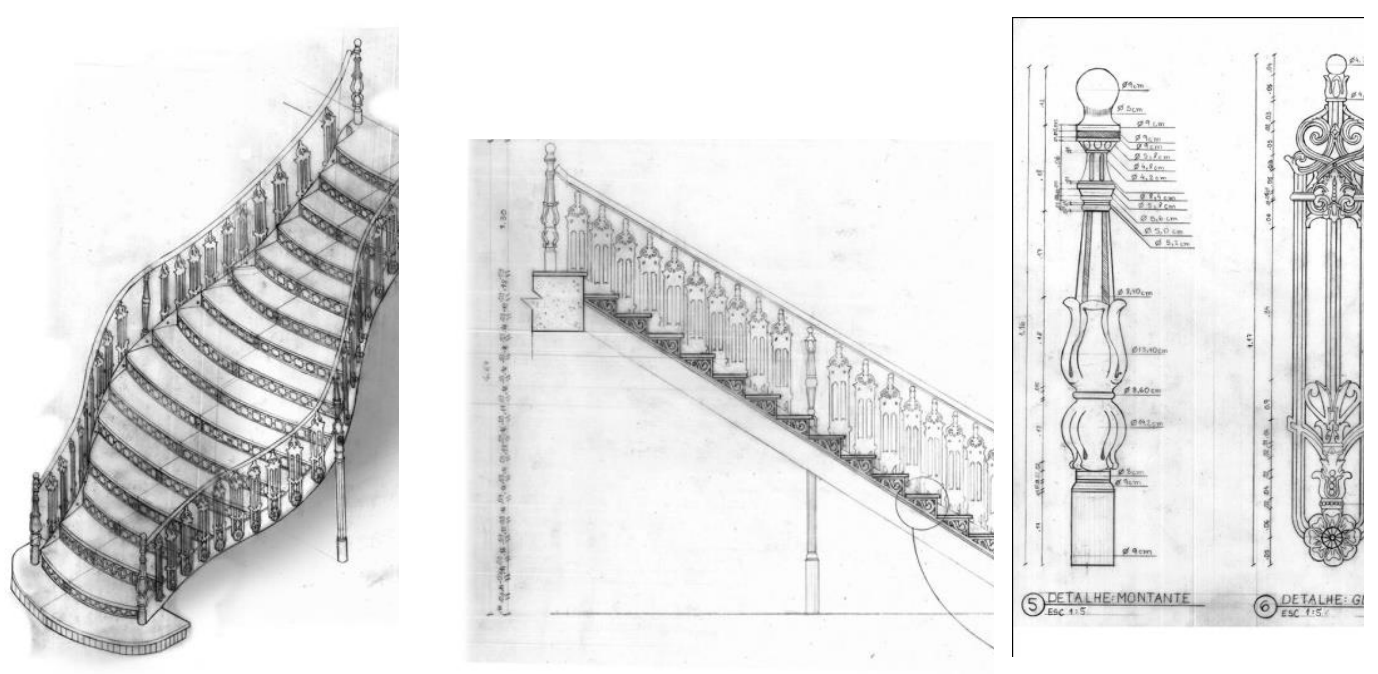

Fonte: Arquivo Disciplina Desenho Arquitetônico, aluno Rodinely Sousa (2016).

Foto 3: Escada do Instituto Histórico e Geográfico do Ceará - levantada pelos alunos.

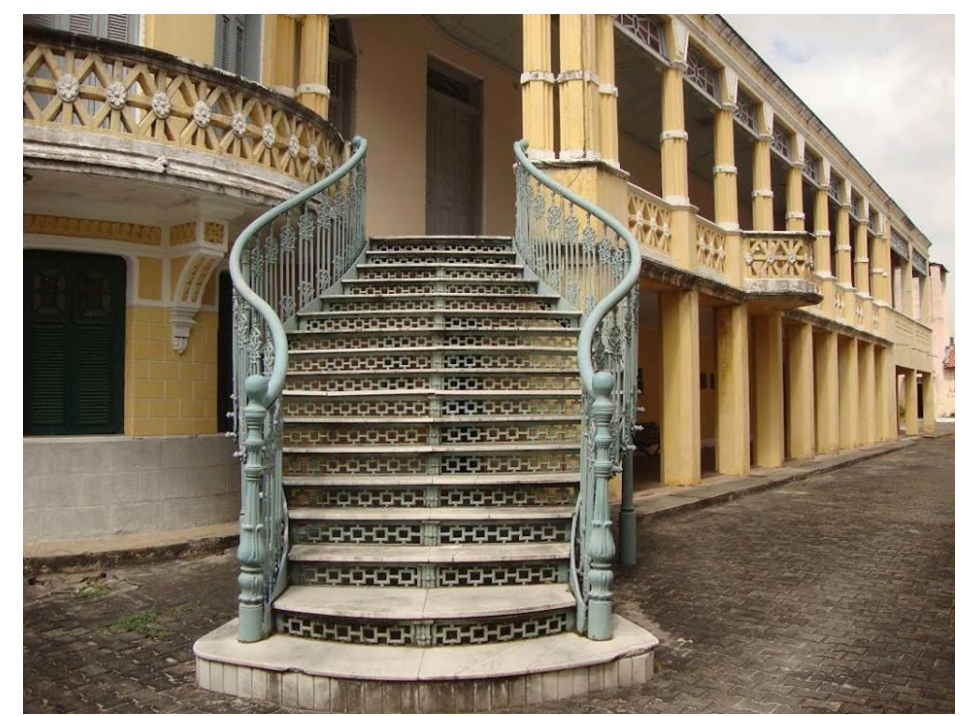

Fonte: Arquivo Disciplina Desenho Arquitetônico, foto aluna Leticia Sampaio (2017). 
Figura 7: Exemplos de desenho final entregue pelos alunos referente ao exercício de esquadrias.

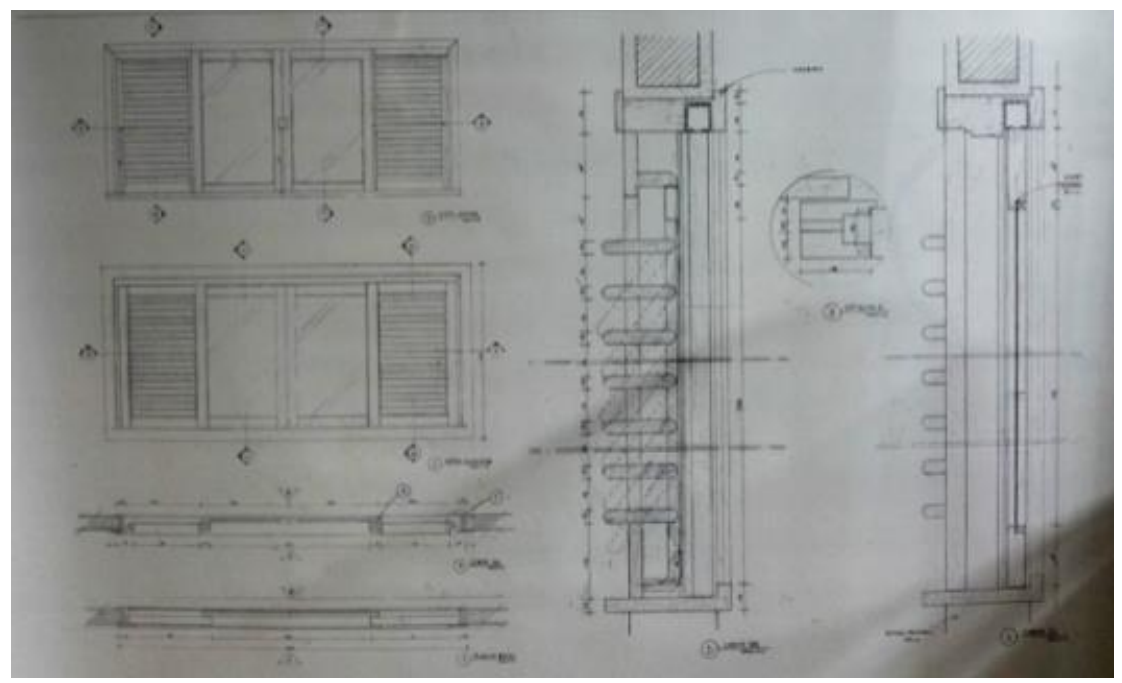

Fonte: Arquivo Disciplina Desenho Arquitetônico (2014).

Figura 8: Exemplos de detalhamento feito pelos alunos referente ao exercício de esquadrias.

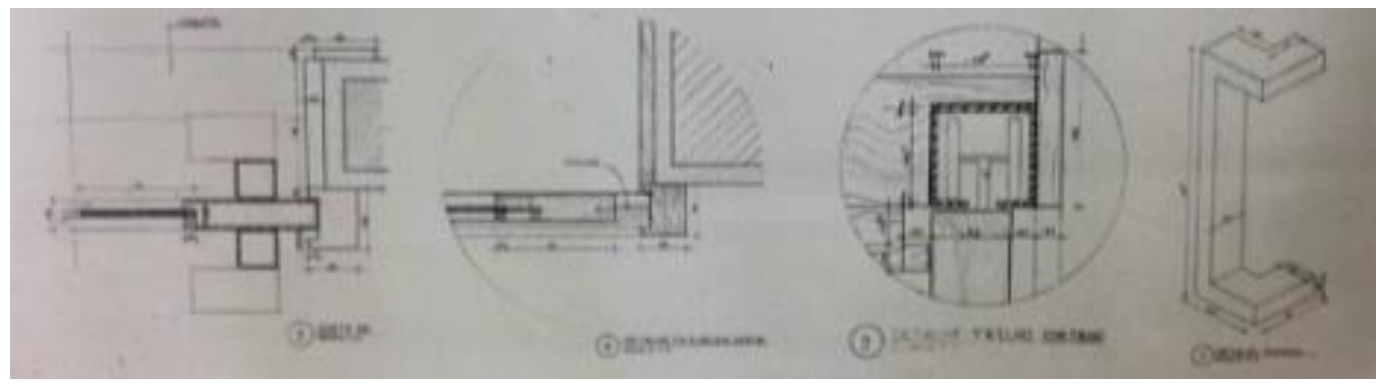

Fonte: Arquivo Disciplina Desenho Arquitetônico (2014).

Até essa etapa o potencial criativo do aluno não é trabalhado, por ser uma etapa de instrumentalização e obtenção de conhecimentos gerais com foco na correta reprodução dos elementos em escala, regras de representação arquitetônica da ABNT (Associação Brasileira de Normas Técnicas) e correta utilização dos instrumentos.

Na última etapa, a representação deixa a escala do objeto e trabalha a escala arquitetônica. Os alunos recebem uma planta do pavimento térreo, onde podem propor modificações e criar o segundo pavimento. Etapa intitulada Representação de Edificação, na qual é desenvolvida uma "reforma", é uma das mais aguardadas pelo aluno por se tratar da primeira experiência de iniciação à prática projetual, mesmo que em nível de simples modificações e ampliações de área construída. Com um maior domínio dos instrumentos e habilitados para melhor perceber o espaço tridimensional, o objetivo desta etapa é levar o aluno a pensar, elaborar e representar modificações, de forma a constituir um projeto básico de uma edificação. Aos poucos vão recebendo orientações sobre conforto e materialidades adequadas, ajudas essas de acordo com o desenvolvimento de cada um e demanda dos questionamentos dos próprios alunos. 
Figura 9: Plantas da prancha final entregue por um dos alunos referente à etapa de reforma.

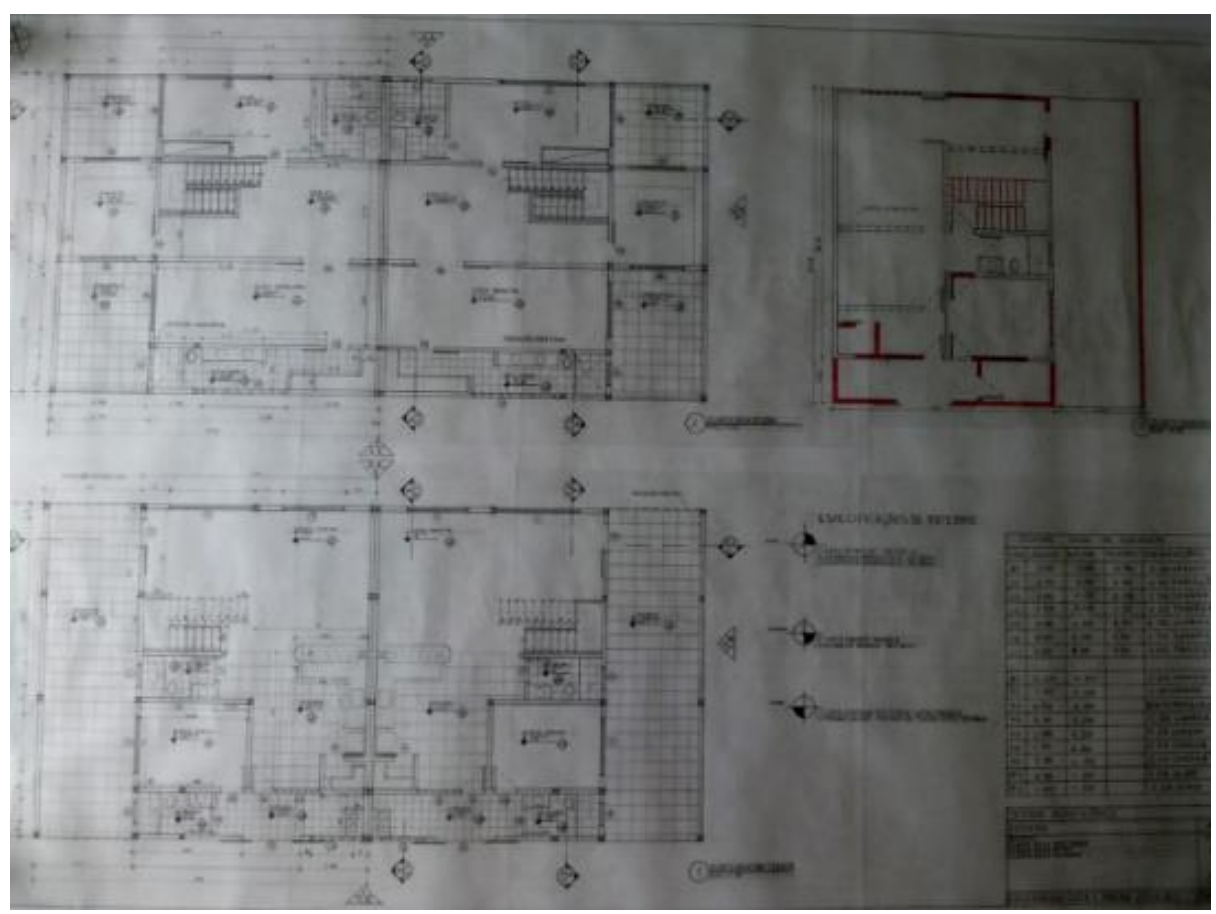

Fonte: Arquivo Disciplina Desenho Arquitetônico (2014).

Figura 10: Cortes da prancha final entregue por um dos alunos referente à etapa de reforma.

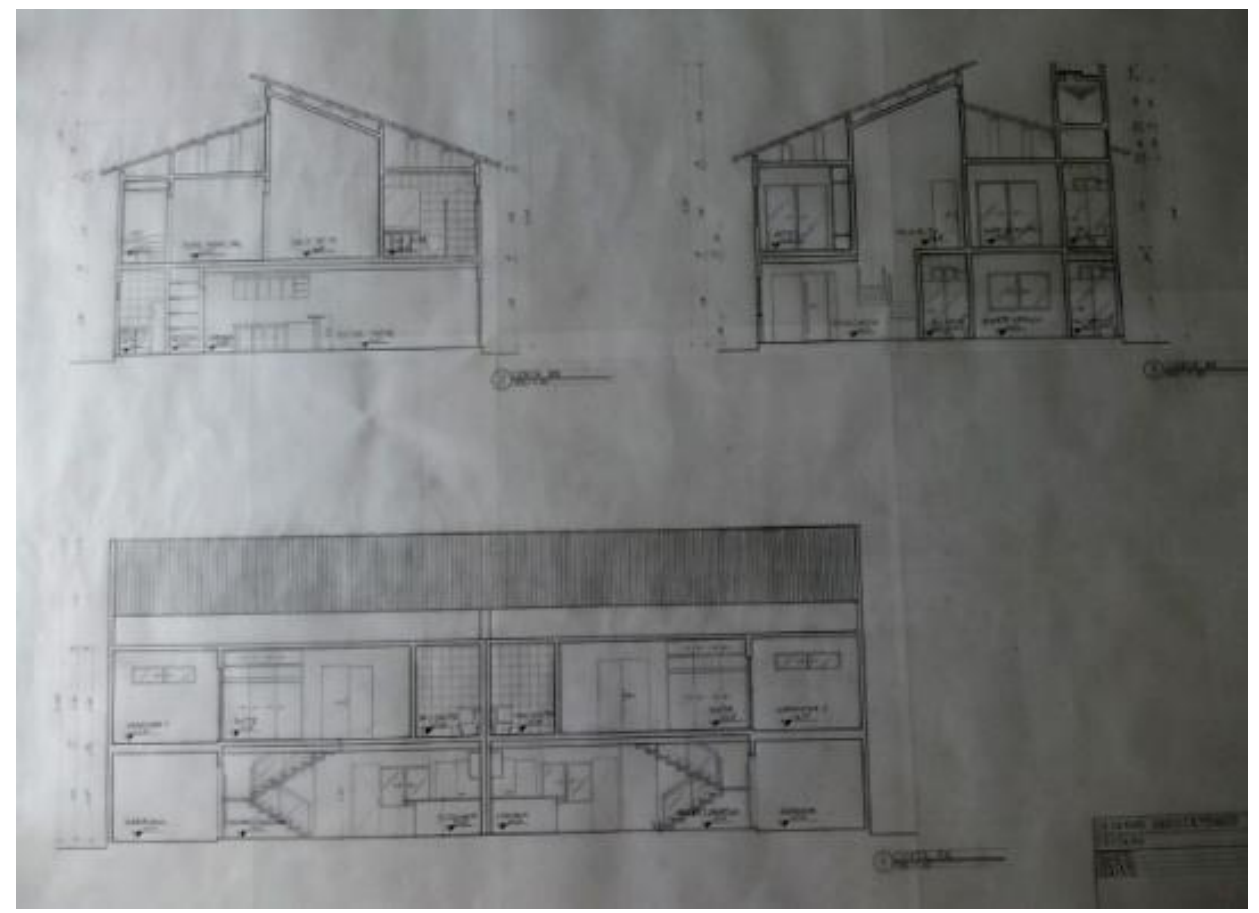

Fonte: Arquivo Disciplina Desenho Arquitetônico (2014).

Através do acompanhamento juntamente com monitores, das atividades ministradas é possível aquilatar a consolidação de conhecimentos vistos ao longo da disciplina, que antes eram tratados de forma teórica e agora são aplicados ao contexto arquitetônico. 
A percepção espacial e apreensão dos detalhes construtivos para alcançar o entendimento da representação gráfica são os principais objetivos alcançados na referida disciplina, destacados pelos próprios alunos, que relatam como a visão da arquitetura se modificou e o interesse pelo detalhes e entendimento das partes que formam um elemento arquitetônico foi estimulada. 0 desenho arquitetônico, pela forma estruturada, e pelo conteúdo necessário a ser abordado, se constitui uma base não só para as disciplinas de projeto, em que se utilizarão da representação arquitetônica, mas para diversas outras por introduzir conceitos, termos e proporcionar noções mínimas de materiais, conforto ambiental, detalhamentos construtivos e acessibilidade. Além disso, destaca-se a importância do ensino-aprendizagem em ateliê, por inserir o aluno em um convívio de aprendizagem entre alunos, numa relação horizontal aluno-aluno e numa relação mais próxima professoraluno, criando uma atmosfera similar ao ambiente de trabalho do fazer arquitetura.

\section{OUTRAS POSSIBILIDADES}

\subsection{Desenho Digital}

É importante citar, embora não seja o foco desse trabalho, de outras possibilidades de desenho além do desenho a mão (seja ele com ou sem instrumento). A atividade do profissional de arquitetura por muito tempo requeria uma intensa habilidade manual, com as mais complexas plantas feitas à mão, com tinta nanquim e papel manteiga. 0 arquiteto ficava sobre a prancheta por horas e horas buscando a representação perfeito de cada traço, hachura e caligrafia.

Esse material era entregue na obra e possibilitava a construção de obras por vários anos até que em 1982 surge um novo conceito em desenho o CAD (computer aided design, ou seja, desenho auxiliado por computador). Utilizando os mesmos conceitos do desenho a mão o desenho feito no computador permitia rapidez e precisão no desenvolvimento dos mesmos elementos feitos a mão: plantas, cortes, fachadas. O princípio era o mesmo: representação abstrata bidimensional com base na geometria mongeana através da representação de linhas.

Por anos o sistema CAD permaneceu em destaque, e ainda hoje é bastante utilizado, mas vem perdendo espaço para um novo conceito em uso de projeto arquitetônico e urbanístico, o BIM. Building Information Modeling ou Modelagem da Informação da Construção é um conceito que vem revolucionando não só o modo que a representação arquitetônica se dá, como também o processo de projeto em Arquitetura. Nessa metodologia, de forma resumida, o profissional ou estudante modela de forma tridimensional o objeto arquitetônico e os desenhos (cortes, plantas e fachadas) são gerados pelo próprio programa.

Independente do sistema utilizado é importante ressaltar que toda a bagagem conceitual do desenho arquitetônico a mão é de extrema importância 
para o entendimento e desenvolvimento dos projetos arquitetônico nos programas virtuais. Por vezes os docentes são indagados pelos alunos o porquê das disciplinas de desenho a mão quando existem diversas tecnologias a serem utilizadas, o que estes precisam entender é que por traz do desenho a mão estão conceitos de representação, percepção, instigação do pensamento espacial, que não ocorreriam se o aluno utilizasse única e exclusivamente o computador. É bem verdade que em seu dia-a-dia os profissionais, salvo exceções que apresentam seus projetos em etapas iniciais de forma mais artísticas, não vão se utilizar e representação de desenhos manuais. Entretanto o croqui, desenho feito de forma rápida para explicação a terceiros ou para desenvolvimento das ideias do arquiteto, sempre será utilizado, independentemente de como será feita a representação técnica.

\subsection{Blended Learning - Ensino-aprendizagem Hibrido}

As novas tecnologias além de propiciarem um avanço tecnológico na representação dos projetos, como a tecnologia BIM, também vem alterando a metodologia de ensino. Não somente com aulas à distância, realidade virtual e simulações. Plataformas de relacionamento vem sendo inseridas cada fez mais como instrumento de comunicações entre docentes e discentes, mesmo quando existe uma plataforma "oficial" da instituição de ensino ou o próprio e-mail.

Podemos citar mídias como o Facebook, rede social lançada em 2004. Hoje, adeptos dos novos tempos, os professores cada vez mais se utilizam da plataforma para manter contato com alunos, distribuir material de estudo e tirar dúvidas. A possibilidade da criação de grupos em uma plataforma na qual os alunos estão sempre conectados, ou acessam com mais frequência, permite maior facilidade nessa troca de informações: o aluno se mostra mais aberto ao conteúdo encaminhado pelo professor, e este se mostra mais acessível ao tirar dúvidas dos alunos por bate-papo. 0 procedimento criativo e a prática protejual são um processos contínuos e uma interação mais instantânea, na qual o docente pode encorajar o aluno no momento em que este se encontra perante uma situação problema e precisa de uma orientação.

Outra plataforma que também vem ganhando adeptos é o Whatsapp, aplicativo de mensagens instantâneas. Ainda mais acessível que o Facebook, este permite a troca rápida de informações, envio de fotos e, mais recentemente, envio de arquivos dos mais diversos formatos. É bastante comum os alunos possuirem grupos para as disciplinas, com ou sem a inclusão do professor, para a troca de conhecimento e ajuda dos colegas sobre o conteúdo. A troca de saberes vem sendo favorecida pelos avanços tecnológicos e se adequando à realidade dos usuários.

\section{CONSIDERAÇÕES FINAIS}

Restabelecer a conexão entre os alunos e o desenho como ferramenta de percepção, experimentação e criação é necessário no início do curso. Como já citado ao longo do texto, as disciplinas que envolvem o desenho inserem 
conceitos que vão muito além do representativo, tratando de questões multidisciplinares e multiperceptivas.

Durante o desenvolvimento das atividades das disciplinas citadas, que são de conteúdo teórico-prático, a metodologia de ateliê auxilia no desenvolvimento das atividades permitindo aos alunos exercitar uma maior autonomia diante dos problemas que se apresentam e, tendo o professor como um facilitador desse processo.

Esse método permite aos alunos que, enquanto criam um repertório de soluções práticas para os problemas padrões, estes também aprendam a modificar suas respostas a cada caso específico, conseguindo resolver problemas os quais nunca teve contato anteriormente.

A tecnologia, além de permitir diversos avanços no que diz respeito à aulas interativas e à simulações para o desenvolvimento dos projetos e sua representação, modificou o modo como a relação entre alunos e professores acontece. A internet, através das redes sociais, mantém aluno e professor mais próximos facilitando a interação fora da sala de aula e melhorando o processo de ensino-aprendizagem.

Através do estudo teórico e do acompanhando da prática de ensino em ateliê de alunos percebemos a importância do desenho no desenvolvimento perceptivo e criativo desses futuros arquitetos e a importância do ensino de forma consistente em seus primeiros semestres para a formação de profissionais capacitados.

Encerramos este relato admitindo que o ateliê como metodologia de ensino-aprendizagem utilizada nos cursos de Arquitetura e Urbanismo é uma estratégia enriquecedora de múltiplas facetas e que, atualmente, pode, com as novas tecnologias expandir as fronteiras do ensino, levando a universidade a expandir as formas de produção do conhecimento, continuando a ser um lugar de ação articulada entre os saberes e que desta forma, com as novas tecnologias ultrapassam as paredes da sala de aula e os muros edificados, conectando e possibilitando uma relação mais horizontal e interativa professor-aluno e ampliando a interatividade entre alunos, bem como possibilitando maior condição de aquisição de conhecimento.

\section{REFERÊNCIAS BIBLIOGRÁFICAS}

ARAÚJO, Ana Carolina Hidalgo. 0 desenhar do arquiteto. Um estudo sobre a utilização do desenho à mão livre como forma de investigação. Instituto de Arquitetura e Urbanismo de São Carlos IAU - USP. São Carlos, 2014.

ASSOCIAÇÃO BRASILEIRA DE NORMAS TÉCNICAS. NBR 6492: Representação de projetos de arquitetura: elaboração. Rio de Janeiro: 1994. 
BATLLE, Alexandre Orzakaukas. 0 papel do desenho na formação e no exercício profissional do arquiteto - conceitos e experiências Dissertação de Mestrado da Faculdade de Arquitetura e Urbanismo de São Paulo. São Paulo. 2011.

ESPÍNDOLA, Rafaela. 0 que é e como funciona o blended learning? Disponível em: https://www.edools.com/blended-learning/ 2016. Acesso em 29/10/2017.

MONTENEGRO, Gildo. Desenho Arquitetônico. São Paulo: Edgard Blücher, 1997.

SANTIAGO, Z. M. P. Prática docente e experiências no atelier de desenho e projeto. In: Anais do XVI Congresso da Sociedade Iberoamericana de Gráfica Digital - SIGRADI. Fortaleza, Br., 2012.

SCHÖN, Donald A. Educando o profissional reflexivo: um novo design para o ensino e a aprendizagem. Trad. Roberto Cataldo Costa. Porto Alegre: Artmed, 2000.

SOUSA, P. G. A representação em projetos de arquitetura. Dissertação ( Mestrado) - Universidade Federal do rio Grande do Norte. Programa de Pós Graduação em Arquitetura e Urbanismo. Natal, 2009.

TAMASHIRO, H. A. Desenho arquitetônico: constatação do atual ensino nas escolas brasileiras de arquitetura e urbanismo. Dissertação ( mestrado) - Escola de Engenharia de São Carlos da Universidade de São Paulo. São Carlos, 2003. 